\title{
EDITORIAL
}

\section{Sizing up stability: combination therapy with Apo-Al peptide mimetics and statins in systemic lupus erythematosus-mediated atherosclerosis}

\author{
Yanice Mendez-Fernandez and Amy Major* \\ See related research by Woo et al., http://arthritis-research.com/content/12/3/R93
}

\begin{abstract}
In a study published recently in Arthritis Research \& Therapy, Woo and colleagues investigated the effects of pravastatin in combination with an apolipoproteinAl (Apo-Al) mimetic peptide in a mouse model of lupus-accelerated atherosclerosis. Combination treatment resulted in a significant decrease in systemic inflammation but increased aortic root lesion size. However, this treatment changed the phenotype of the lesion to a more stable plaque. Because plaque stability is also important for protection against the deadly manifestations of atherosclerosis, combination therapies using Apo-Al mimetics and statin might offer a good additional therapy to treat autoimmunity and cardiovascular disease in patients with lupus.
\end{abstract}

Systemic lupus erythematosus (SLE) (lupus) is a chronic autoimmune disease characterized by the production of autoantibody against several self-antigens such as double-stranded DNA (dsDNA), phospholipids, and apolipoproteins. Individuals suffering from lupus usually develop a myriad of comorbidities, including hemolytic anemia, neuropathies, glomerulonephritis, and cardiovascular disease (CVD). In the mid-1970s, Urowitz and colleagues [1] demonstrated a bimodal mortality in which individuals who died soon after diagnosis usually succumbed to either kidney disease or infection (due to extensive immunosuppressive therapy) whereas those who survived longer past diagnosis most likely developed CVD. In 1997, a seminal paper by Manzi and colleagues [2] reported for the first time that the risk for developing

${ }^{*}$ Correspondence: amy.major@vanderbilt.edu

Department of Medicine/Divison of Cardiovascular Medicine, Venderbilt University Medical Center. 2220 Pierce Avenue, Nashville, TN 37232-6300, USA
CVD and myocardial infarction is significantly increased in premenopausal women. Since that time, numerous studies have described the existence of premature subclinical and accelerated atherosclerosis in patients with lupus (reviewed in [3]). To make matters worse, many patients with lupus do not exhibit the traditional risk factors for atherosclerosis, namely increased lowdensity lipoprotein (LDL) cholesterol and decreased high-density lipoprotein (HDL) cholesterol. Instead, most patients develop dyslipidemia characterized by increased triglyceride and slight decreases in HDL but no significant increase in LDL cholesterol. Therefore, it is possible that the traditional LDL-lowering therapies that have been so successful in treating CVD and atherosclerosis in the general population may not have the same effect in patients with lupus.

By now, it is commonly accepted that HDL and apolipoprotein-AI (Apo-AI) are cardio-protective in both humans and mouse models of atherosclerosis. However, it was recently demonstrated that individuals suffering from active SLE can develop a dysfunctional HDL defined as inflammatory HDL [4]. This modified lipoprotein is characterized by reduced concentrations of Apo-AI and paraoxonase, molecules important for mobilizing cholesterol from cells and protecting LDL from oxidative modifications, respectively. Therefore, patients with SLE have a particular disadvantage in both levels and phenotype of protective HDL.

Owing to the cardio-protective nature of Apo-AI, research has been focused on developing effective ApoAI-based therapies for CVD. One approach shown to be effective in reducing atherosclerosis and systemic inflammation in mice is the use of synthetic peptides that mimic Apo-AI in both structure and function [5,6]. These mimetics, termed D-4F and L-4F, can increase the ability of HDL cholesterol to protect LDL from oxidation, increase HDL levels, and increase cholesterol efflux from cells [7]. Therefore, it is a logical extension that these peptides should be tested for their abilities to increase 
not only the quantity but also the quality of HDL in SLE as a possible mechanism of protection from accelerated atherosclerosis.

Undoubtedly, one of the most popular, and successful, therapies for the management of CVD and lipids in the general population has been the use of statins. Given that statins have had positive clinical effects in patients with rheumatoid arthritis, it is logical to expect that individuals with SLE would likewise benefit from this therapy [8]. Unfortunately, the clinical studies testing statin use in patients with SLE have not been very promising [9]. In a study published recently in Arthritis Research \& Therapy, Woo and colleagues [10] investigated whether statin therapy might have positive effects in a mouse model of lupus-mediated accelerated atherosclerosis and osteoporosis.

In that study, Woo and colleagues [10] tested the hypothesis that treatment of apoE-deficient $\left(\mathrm{apoE}^{-/-}\right)$ mice lacking Fas (hereafter referred to as apoE $\mathrm{E}^{-/-} \mathrm{Fas}^{-/-}$), with a high-dose statin, pravastatin $(5 \mathrm{mg} / \mathrm{kg})$, either alone or in combination with the Apo-AI mimetic, L-4F, could decrease the progression of atherosclerosis and have positive effects on osteoporosis. The authors observed, in agreement with the anti-inflammatory properties of Apo-AI, a decrease in autoantibody titers to dsDNA and oxidized phospholipid as well as a reduction in glomerulus tuft size, proteinuria, and lymphocyte infiltration in mice treated with L-4F or L-4F plus pravastatin compared with the vehicle-treated group. Surprisingly, the anti-inflammatory effect of this treatment was accompanied by an increase in aortic root atherosclerotic lesion area in apoE ${ }^{-1-} \mathrm{Fas}^{-1-}$ mice that received L-4F, pravastatin, or combination therapy, despite reduced interleukin-10 and chemokine levels and decreased VCAM-1 (vascular cell adhesion molecule-1) expression on endothelial cells. This effect was independent of circulating lipoprotein levels. Interestingly, combination therapy, but not L-4F or pravastatin therapy alone, resulted in decreased macrophage infiltration and plaque remodeling, suggestive of a more stable plaque. Furthermore, L-4F therapy resulted in the improvement of bone density in these mice. Because plaque stability and not just plaque size is important for protection against the deadly manifestations of atherosclerosis (a view that is commonly accepted), combination therapies using Apo-AI mimetics and statin might offer a good additional therapy to treat autoimmunity and associated CVD and osteoporosis in patients with SLE.

Collectively, the findings of Woo and colleagues [10] represent a glimmer of hope for a group of patients who have not had a major breakthrough in treatment in the past 30 years. Patients with SLE are subject to a large number of comorbidities; two of the more severe comorbidities are accelerated atherosclerosis and increased risk of myocardial infarction. Although L-4F and other Apo-AI mimetics may have positive effects on SLE symptoms and plaque stability, the increase in total lesion area obviously represents a significant hurdle for the practical use of these molecules in the clinic.

\section{Abbreviations}

Apo-Al, apolipoprotein-Al; CVD, cardiovascular disease; dsDNA, doublestranded DNA; HDL, high-density lipoprotein; LDL, low-density lipoprotein; SLE, systemic lupus erythematosus.

Competing interests

The authors declare that they have no competing interests.

Published: 15 September 2010

\section{References}

1. Urowitz MB, Bookman AA, Koehler BE, Gordon DA, Smythe HA, Ogryzlo MA: The bimodal mortality pattern of systemic lupus erythematosus. Am J Med 1976, 60:221-225.

2. Manzi S, Meilahn EN, Rairie JE, Conte CG, Medsger TA Jr., Jansen-McWilliams L, D'Agostino RB, Kuller LH: Age-specific incidence rates of myocardial infarction and angina in women with systemic lupus erythematosus: comparison with the Framingham Study. Am J Epidemiol 1997, 145:408-415.

3. Roman MJ, Shanker BA, Davis A, Lockshin MD, Sammaritano L, Simantov R, Crow MK, Schwartz JE, Paget SA, Devereux RB, Salmon JE: Prevalence and correlates of accelerated atherosclerosis in systemic lupus erythematosus. NEngl J Med 2003, 349:2399-2406.

4. Waldmann H, Hu TS, Renner S, Menninger S, Tannert R, Oda T, Arndt HD: Total synthesis of chondramide $\mathrm{C}$ and its binding mode to F-actin. Angew Chem Int Ed Engl 2008, 47:6473-6477.

5. Navab M, Anantharamaiah GM, Hama S, Garber DW, Chaddha M, Hough G, Lallone R, Fogelman AM: Oral administration of an Apo A-I mimetic peptide synthesized from $D$-amino acids dramatically reduces atherosclerosis in mice independent of plasma cholesterol. Circulation 2002, 105:290-292.

6. Gupta H, Dai L, Datta G, Garber DW, Grenett H, Li Y, Mishra V, Palqunachari MN, Handattu S, Gianturco SH, Bradley WA, Anantharamaiah GM, White CR: Inhibition of lipopolysaccharide-induced inflammatory responses by an apolipoprotein Al mimetic peptide. Circ Res 2005, 97:236-243.

7. Sherman CB, Peterson SJ, Frishman WH: Apolipoprotein A-I mimetic peptides: a potential new therapy for the prevention of atherosclerosis. Cardiol Rev 2010, 18:141-147.

8. Paraskevas Kl: Statin treatment for rheumatoid arthritis: a promising novel indication. Clin Rheumatol 2008, 27:281-287.

9. de Kruif MD, Limper M, Hansen HR, de Ruiter J, Spek CA, van Gorp EC, ten Berge IJ, Rowshani AT, ten Cate H, Meesters EW: Effects of a 3-month course of rosuvastatin in patients with systemic lupus erythematosus. Ann Rheum Dis 2009, 68:1654.

10. Woo JM, Lin Z, Navab M, Van Dyck C, Trejo-Lopez Y, Woo KM, Li H, Castellani LW, Wang X, likuni N, Rullo OJ, Wu H, La Cava A, Fogelman AM, Lusis AJ, Tsao BP: Treatment with apolipoprotein A-1 mimetic peptide reduces lupus-like manifestations in a murine lupus model of accelerated atherosclerosis. Arthritis Res Ther 2010, 12:R93.

\section{doi:10.1186/ar3115}

Cite this article as: Mendez-Fernandez Y, Major A: Sizing up stability: combination therapy with Apo-Al peptide mimetics and statins in systemic lupus erythematosus-mediated atherosclerosis. Arthritis Research \& Therapy 2010, 12:139. 